\title{
Modestly degraded microarchitecture and high serum levels of osteopontin in Swedish females with anorexia nervosa
}

\author{
Pär Wanby ${ }^{1,2,3}$ (1) $\cdot$ Lars Brudin $^{4,5} \cdot$ Siv-Ping Von ${ }^{6} \cdot$ Martin Carlsson $^{6,7}$
}

Received: 2 July 2020 / Accepted: 22 October 2020 / Published online: 6 November 2020

(c) The Author(s) 2020

\begin{abstract}
Purpose Adult women with long-time anorexia nervosa (AN) are believed to have osteopenia (T-score $\leq 1.0$ ) in $93 \%$ and osteoporosis (T-score $\leq 2.5$ ) in $38 \%$. Bone microarchitecture assessed by Trabecular Bone Score (TBS) predicts osteoporotic fractures. Our aim was to evaluate the microarchitecture in adult females with AN by determining TBS and to identify factors potentially associated with TBS, such as bone turnover markers.

Methods 20 female patients with AN (DSM IV), aged $27.8 \pm 4.4$ years, BMI $16.6 \pm 0.6 \mathrm{~kg} / \mathrm{m}^{2}$ and duration of illness of $8.5 \pm 5$ years had previously been evaluated with dual-energy X-ray absorptiometry (DXA). TBS measurements were now obtained, using iNsight software, from spinal DXA images. Serum levels of bone turnover markers were determined in patients and healthy normal-weight controls.

Results Compared to controls serum values of osteopontin were higher $(p=0.009)$. BMD in patients with AN was reduced by at least $1.0 \mathrm{SD}$ at one or more skeletal sites in $65 \%$ of patients and by at least $2.5 \mathrm{SD}$ in $20 \%$. Only one of the patients $(5 \%)$ had suffered a fracture. TBS (mean $1.35 \pm 0.06$; median $1.36(1.23-1.44)$ was in the lower normal range $(\geq 1.35)$. 40 $\%$ of patients showed partially $(>1.20$ and $<1.35)$ but none showed a fully degraded micro-architecture.

Conclusions In Swedish AN patients we found a low reduction of BMD and fracture history. The bone microarchitecture, evaluated for the first time for this group by TBS, was only modestly compromised, and to a lesser extent than expected for this group of patients with AN.

Level of evidence Level V; cross-sectional descriptive study.
\end{abstract}

Keywords Anorexia nervosa $\cdot$ Microarchitecture $\cdot$ TBS $\cdot$ Osteopontin $\cdot$ Dkk-1

\section{Introduction}

Anorexia nervosa (AN) is characterized by low-fat mass, often complicated by reduction of bone mass, impaired bone structure, and fractures [1]. As an adaptation to chronic

Pär Wanby

par.wanby@regionkalmar.se

Lars Brudin

lars.brudin@egionkalmar.se

Siv-Ping Von

sivping.von@regionkalmar.se

Martin Carlsson

martin@accumbo.se

1 Department of Medicine and Optometry, Linnaeus University, SE, 39182 Kalmar, Sweden

2 Department of Medical and Health Sciences, University of Linköping, SE, 58183 Linköping, Sweden undernutrition, multiple endocrine abnormalities develop with a profound impact on bone metabolism, and a compromised bone mineral density (BMD) is a hallmark of AN [2]. Adult women with long-term AN [3] are believed to have osteopenia (T-score $\leq 1.0$ ) in $93 \%$ and osteoporosis (T-score

3 Department of Internal Medicine, Section of Endocrinology, Region Kalmar County, 39244 Kalmar, Sweden

4 Department of Medical and Health Sciences, University of Linköping, SE, 58183 Linköping, Sweden

5 Department of Clinical Physiology, Region Kalmar County, SE, 39244 Kalmar, Sweden

6 Department of Clinical Chemistry, Region Kalmar County, SE, 39244 Kalmar, Sweden

7 Department of Medicine and Optometry, Linnaeus University, SE, 39182 Kalmar, Sweden 
$\leq 2.5$ ) in approximately $40 \%$. When AN develops during adolescence peak bone accrual is often suboptimal [4] and BMD tends to be even lower than in those who develop AN in adulthood, despite a similar duration of amenorrhea [5]. However, regardless of age, fracture risk is increased for this condition and is also increased in women with a past history of AN $[1,6]$.

BMD is measured by dual-energy X-ray absorptiometry (DXA) and is a major determinant of fracture risk [4], although BMD only explains $60-80 \%$ of all fractures in postmenopausal females [7, 8]. Skeletal factors other than BMD, such as microarchitecture, also contribute to bone strength and fracture risk. In adolescent girls with $\mathrm{AN}$, as well as in adult women with AN, impaired microarchitecture has been demonstrated with flat-panel ultra-high-resolution volume computed tomography [9]. Trabecular bone score (TBS) is a grey-level textural index that captures elements of three-dimensional bone architecture such as trabecular number and separation that are not obtained in a standard DXA measurement [10, 12], but obtainable from spinal DXA data. TBS is thus an easily accessible, non-invasive method that offers information beyond that which DXA BMD measurements provide, and in post-menopausal women TBS predicts fracture risk [11]. Evidence of degraded bone microarchitecture, expressed as reduced levels of TBS, has been demonstrated in adolescent girls [13, 14], but not, to our knowledge, in adult patients with AN.

The aim of this study was to evaluate the microarchitecture in a group of adult Swedish females with AN, by determining TBS. A secondary aim was to identify clinical and biochemical factors, such as bone turnover markers, and their potential association with TBS.

\section{Methods}

Twenty female patients with AN (DSM IV), aged $27.8 \pm 4.4$ years, with a BMI of $16.6 \pm 0.6 \mathrm{~kg} / \mathrm{m}^{2}$ and a duration of illness of 8 years $(0.5-21)$, had been previously included in a vitamin D study (2013-16) at an outpatient clinic in southeastern Sweden specializing in the treatment of eating disorders [15], and at inclusion were evaluated with DXA (GE Lunar iDXA). Following the availability of TBS measurements the patients were included in the present study, and TBS measurements were obtained retrospectively from spinal DXA images of the patients with AN, using iNsight software. Neither patients on medication nor with a chronic disease affecting bone health, nor pregnant patients were included in the study [15].

BMD was determined by dual emission X-ray absorptiometry (DXA) of the total hip and lumbar region (GE Lunar iDXA (GE Healthcare Lunar, Madison, WI), with a precision of $0.007 \mathrm{~g} / \mathrm{cm}^{2}(\mathrm{CV}=0.5 \%)$ [16]. TBS values $\geq$
1.35 were considered normal, $>1.20$ and $<1.35$ partially degraded, and $\leq 1.20$ degraded microarchitecture [7, 13].

Bone turnover markers were assessed in the twenty patients with $\mathrm{AN}$ and in a control group consisting of 78 healthy female blood donors (age $22.6 \pm 2.0$ years, BMI $24.9 \pm 4.7 \mathrm{~kg} / \mathrm{m}^{2}$ ) that volunteered for the study. This healthy control group has also been previously presented [15].

All participants had given their written informed consent to participate in the study, which had received the approval of the Regional Ethical Committee, Linköping, Sweden.

\section{Assays}

Non-fasting venous blood samples were drawn for analysis. Free vitamin D $(25(\mathrm{OH}) \mathrm{D})$ was determined by an ELISA method (Future Diagnostics Solutions B.V, Netherlands). For details regarding assays determining total serum $25(\mathrm{OH})$ $\mathrm{D}$, plasma calcium, serum ionized calcium, serum PTH, plasma albumin, plasma creatinine, and serum leptin, see reference [15].

Serum testosterone, Luteinizing Hormone (LH), FollicleStimulating Hormone (FSH) plasma Thyroid-Stimulating Hormone (TSH) and free plasma tyroxin (T4) were analyzed using the instrument Cobas e601 electrochemiluminescence immunoassays from Roche Diagnostics, Basel, Switzerland. Blood samples were analyzed for plasma alkaline phosphatase (ALP) using the instrument AU680, Beckman Coulter, Brea, CA, USA.

Bone turnover marker analysis (Dickkopf-1 [Dkk-1], Osteoprotegerin [OPG], Osteocalcin, and Osteopontin [OPN] was performed simultaneously according to Merck Millipore's instructions for the XMAP technology with multiplex beads. Plates (Human Bone Magnetic Bead Panel from Merck Millipore) were measured using the Luminex's XMAP® instrument MagPix LX 200 (Luminex, Austin, TX, USA). All samples were analysed in duplicates. If duplicate results differed by more than $20 \%$ measurements were repeated on a second aliquot. The controls were analysed in the beginning and end of each plate. The coefficients of variation (\% CVs) were for Dkk-1: 2,7; OPG: 2,7; osteocalcin: 6,3 ; OPN: 8,3.

\section{Statistical analysis}

All continuous variables are presented as the mean (SD) and median (range). Student's test or the Chi-square test was used to compare serum values of bone turnover markers in patients with anorexia and controls. Correlations between trabecular bone score (TBS) and other various variables assessed at study inclusion were calculated using Spearman's non-parametric regression. Statistical analyses were performed with STATISTICA (version 12, Statsoft ${ }^{\circledR}$, 
Tulsa, USA), and p-values $<0.05$ were considered statistically significant.

\section{Results}

Clinical characteristics of the 20 patients with AN are summarized in Table 1.

Patients with AN had low values of hip bone mineral density (BMD; $0.85 \pm 0.13 \mathrm{~g} / \mathrm{cm}^{2}$, T-score -1.26 $\pm 1.09, \mathrm{Z}$-score $-0.83 \pm 1.08)$ and lumbar spinal BMD $\left(0.99 \pm 0.09 \mathrm{~g} / \mathrm{cm}^{2}, \mathrm{~T}\right.$-score $-1.77 \pm 0.78$ and Z-score $-1.01 \pm 0.75) .40$ and $65 \%$ in the hip and lumbar spine, respectively, were osteopenic, 15 and $20 \%$ were osteoporotic, respectively (Table 1). BMD was reduced by at least 1.0 SD at one or more skeletal sites in $65 \%$ of patients and by at least $2.5 \mathrm{SD}$ in $20 \%$ of patients. Only one of the patients $(5 \%)$ had suffered a fracture.

Serum values for leptin and bone turnover markers in patients with AN and controls are presented in Table 2. Serum values for leptin $(p>0.001)$ and DKK-1 $(p=0.047)$ were lower in patients with AN while serum values for osteopontin were higher $(p=0.009)$.

TBS (mean $1.35 \pm 0.06$; median $1.36(1.23-1.44$ ) was in the lower normal range $(\geq 1.35) .40 \%$ of patients showed partially $(>1.20$ and $<1.35)$ degraded microarchitecture. None showed a fully degraded microarchitecture.

TBS was negatively associated with the age of menarche $(p=0.008)$ and positively associated with BMI $(p=0.017)$, BMD of the hip $(p=0.013)$, hip T- and Z-scores $(p=0.013$ and $p=0.010$, respectively) but not with the duration of AN or BMD of the lumbar spine ( $p=0.110$ ), nor with any of the bone turnover markers (Table 3 ).

\section{Discussion}

In this study, conducted in a small population of young Swedish female adults with a long duration of AN we assessed microarchitecture using TBS. The major finding was only a modestly compromised TBS in accordance with an unexpectedly low reduction of BMD and fracture history.

The utility of TBS has been evaluated in several populations studies [10-12, 17-20], but to the best of our knowledge this is the first study to test the practicality of deriving TBS from lumbar spinal DXA scans to assess microarchitecture in adult patients with AN. Previously, this has been tested in numerous populations but in AN only among adolescent patients $[13,14]$. TBS was, in these two studies, partially degraded in $33 \%$ and $59 \%$, and degraded in an additional $11 \%$ and $8 \%$, respectively. The mean patient age of both these studies was about 15.5 years with an illness duration of 4 months and 2 years, a mean BMI of $18.9 \pm 1.8$ and $15.9 \pm 2.2 \mathrm{~kg} / \mathrm{m}^{2}$, respectively. In our study of young adult females with a mean BMI of $16.6 \pm 0.6 \mathrm{~kg} / \mathrm{m}^{2}, 40 \%$ had a partially degraded microarchitecture despite a much longer duration of AN. The more pronounced reduction in TBS in the later study of adolescents with AN may be due to a lower BMI, or to the more deleterious effects of AN on the bone when encountered during bone mass acquisition as to when AN develops in adulthood [4, 5]. It is uncertain whether this also translates to bone microarchitecture.

In both aforementioned studies of paediatric patients with AN $[13,14]$, numerous correlations with anthropomorphic and clinical variables were demonstrated. In our study, we found an association between TBS with the age of menarche, BMI, and DXA measures of the hip, but not with the lumbar spine. The low number of patients could have contributed to the lack of association to lumbar spine parameters as to a previously demonstrated association between trabecular microarchitecture and disease duration [21]. Leptin and testosterone, for which we found no association to TBS, has furthermore been demonstrated to, independent of BMI, predict bone microarchitecture [22].

In an often-cited study by Grinspoon and colleagues BMD was, in women with a mean age of 24 years, a mean duration of AN of more than 5 years, and a mean BMI of $17.1 \mathrm{~kg} / \mathrm{m}^{2}$, reduced by at least $1.0 \mathrm{SD}$ at one or more skeletal sites in $92 \%$ of patients, and by at least $2.5 \mathrm{SD}$ in 38 $\%$ [3]. In a subsequent study by Miller and co-workers in patients with a similar patient age and illness duration (mean BMI $16.8 \mathrm{~kg} / \mathrm{m}^{2}$ ), corresponding percentage figures were 86 and 34, respectively [23]. In our patients BMD was to a lesser degree compromised; $65 \%$ were either osteopenic or osteoporotic and $20 \%$ osteoporotic. Our finding of a less reduced BMD in adult patients (mean age 27.8 \pm 4.4 ) with AN compared to previous studies can most likely be explained by our small study population, and an unexpectedly low fracture incidence, $5 \%$ in comparison to $30 \%$ [24], supports this line of reasoning. On the other hand, although small, our group of patients with a long duration of illness and a rather low BMI represents a sample with, in many respects, relatively severe AN. Parameters of bone health were thus expected to be likewise, which makes our findings unexpected. Moreover, the cited studies [3, 23] were performed at the beginning of this century, and more recent studies of BMD in adult patients with AN are scant. Larger studies in adult patients with AN are thus warranted to clarify representative levels of BMD affection as well as the extent of TBS degradation and the potential role of TBS in fracture prediction for this condition.

In this study, we measured several bone turnover markers previously not fully characterized in $\mathrm{AN}$, nor in relation to bone architecture in particular. We could not demonstrate any correlations between TBS and bone turnover markers, but as anticipated we found decreased serum levels of the 
Table 1 Clinical characteristics in 20 patients with anorexia nervosa (AN); previously in part published by Carlsson et al [15]

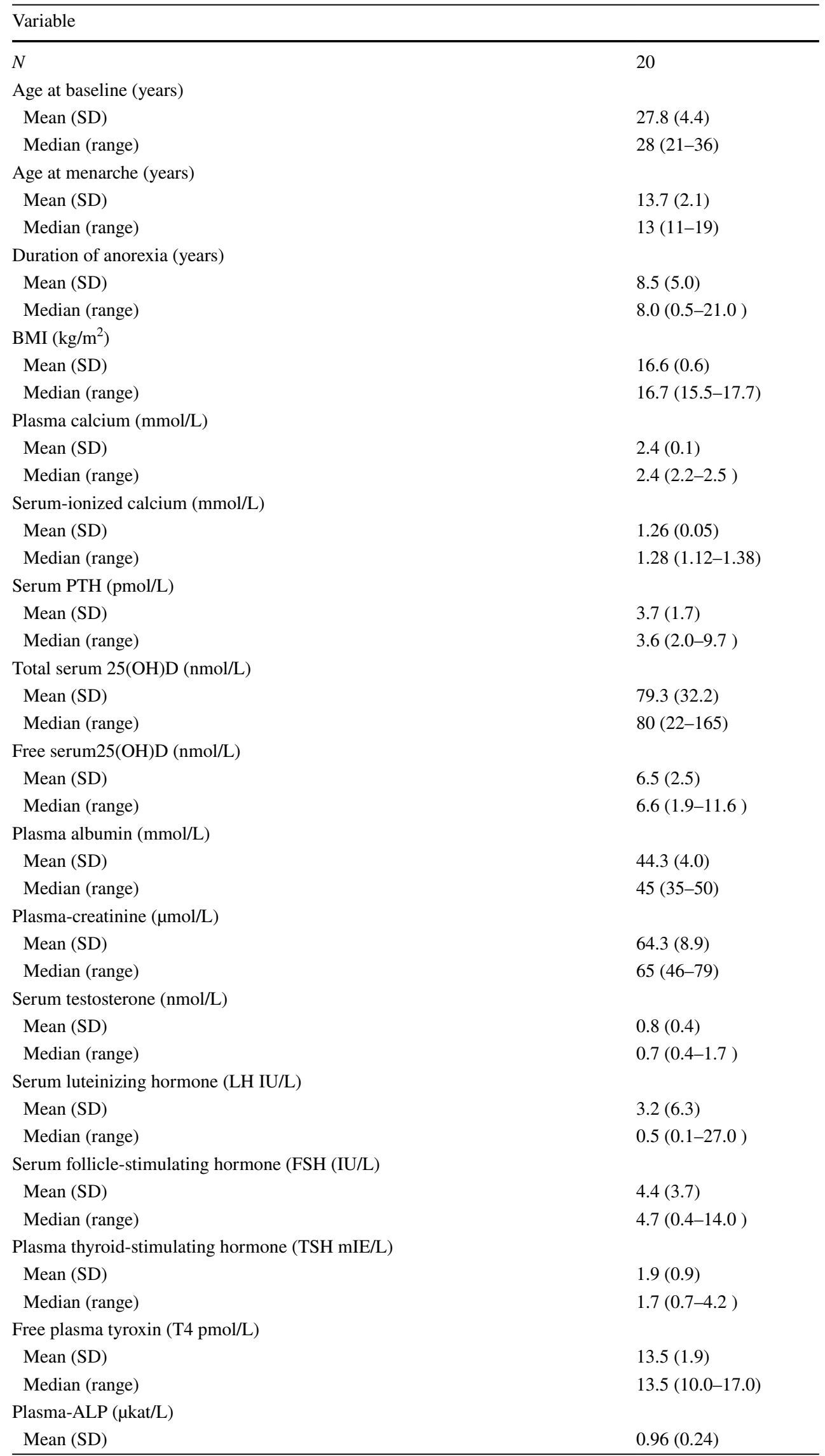


Table 1 (continued)

\begin{tabular}{|c|c|}
\hline Variable & \\
\hline Median (range) & $0.9(0.6-1.4)$ \\
\hline \multicolumn{2}{|c|}{ Bone mineral density hip $\left(\mathrm{g} / \mathrm{cm}^{2}\right)$} \\
\hline Mean (SD) & $0.85(0.13)$ \\
\hline Median (range) & $0.86(0.57-1.07)$ \\
\hline \multicolumn{2}{|l|}{ T-score Hip } \\
\hline Mean (SD) & $-1.26(1.09)$ \\
\hline Median (range) & $-1.17(-3.58$ to 0.59$)$ \\
\hline \multicolumn{2}{|l|}{ Z-score Hip } \\
\hline Mean (SD) & $-0.83(1.08)$ \\
\hline Median (range) & $-0.67(-3.15$ to 1.15$)$ \\
\hline \multicolumn{2}{|c|}{ Bone mineral density lumbal $\left(\mathrm{g} / \mathrm{cm}^{2}\right)$} \\
\hline Mean (SD) & $0.99(0.09)$ \\
\hline Median (range) & $1.01(0.78-1.12)$ \\
\hline \multicolumn{2}{|l|}{ T-score_lumbal } \\
\hline Mean (SD) & $-1.77(0.78)$ \\
\hline Median (range) & $-1.61(-3.54$ to -0.67$)$ \\
\hline \multicolumn{2}{|l|}{ Z-score lumbal } \\
\hline Mean (SD) & $-1.01(0.75)$ \\
\hline Median (range) & $-0.87(-2.84$ to 0.13$)$ \\
\hline \multicolumn{2}{|c|}{ Trabecular bone score (TBS) } \\
\hline Mean (SD) & $1.35(0.06)$ \\
\hline Median (range) & $1.36(1.23-1.44)$ \\
\hline \multicolumn{2}{|c|}{ BMD hip category $(n, \%)$} \\
\hline Osteoporosis & $3(15.0)$ \\
\hline Osteopenia & $8(40.0)$ \\
\hline Normal & $9(45.0)$ \\
\hline \multicolumn{2}{|c|}{ BMD lumbal category $(n, \%)$} \\
\hline Osteoporosis & $4(20.0)$ \\
\hline Osteopenia & $13(65.0)$ \\
\hline Normal & $3(15.0)$ \\
\hline Osteoporosis & $4(20.0)$ \\
\hline Osteopenia & $13(65.0)$ \\
\hline Normal & $3(15.0)$ \\
\hline
\end{tabular}

Wnt signalling pathway inhibitor, DKK-1 [25]. For OPG we measured increased serum levels, which confirms a finding by Ostrowska et al [26], although in patients with $\mathrm{AN}$ an increased secretion of RANKL, and decreased levels would be expected due to estrogen deficiency [27].

Osteopontin (OPN) is a non-collagenous matrix protein expressed in bone tissue, which is involved in bone remodeling and capable of activating bone resorption [28]. Osteopontin has been associated with increased fracture risk in postmenopausal women, but previous reports on serum levels in subjects with AN are lacking. Our finding of highly increased levels of Osteopontin in AN are expected but may represent a novel finding requiring further research.

Some limitations of the study must be acknowledged. Foremost, our group of patients was small and consisted of only female participants, which limits the generalizability of the study, and may explain the lack of associations with various secondary variables such as lumbar spinal DXA values and serum levels of bone turnover markers. Furthermore, we did not obtain DXA scans and, consequently, no TBS values from healthy controls. Instead, we compared TBS measurements with healthy postmenopausal women, which may result in an underestimation of the extent of the microarchitectural degradation in young adult females with AN.

\section{Conclusions}

In adult patients with $\mathrm{AN}$, bone microarchitecture, evaluated in this group for the first time by TBS, was only modestly compromised and did not correlate to a novel finding of increased serum levels of osteopontin. These findings 
Table 2 Serum leptin and bone turnover markers in patients with anorexia nervosa (AN) and controls

\begin{tabular}{|c|c|c|c|}
\hline Variable & Anorexia & Controls & $\operatorname{Diff}(p)$ \\
\hline$N$ & 20 & 78 & - \\
\hline \multicolumn{4}{|c|}{ Age at baseline (years) } \\
\hline Mean (SD) & $27.8(4.4)$ & $22.6(2.0)$ & \\
\hline Median (range) & $28(21-36)$ & $22(19-26)$ & $<0.001$ \\
\hline \multicolumn{4}{|c|}{ BMI-baseline $\left(\mathrm{kg} / \mathrm{m}^{2}\right)$} \\
\hline Mean (SD) & $16.6(0.6)$ & $24.9(4.7)$ & \\
\hline Median (range) & $16.7(15.5-17.7)$ & $24.2(18.1-39.6)$ & $<0.001$ \\
\hline \multicolumn{4}{|c|}{ Dickkopf-1 (Dkk-1; ng/L) } \\
\hline Mean (SD) & $2247.4(684.0)$ & $2596.5(737.0)$ & \\
\hline Median (range) & $1937(1302-3692)$ & $2506(1203-5603)$ & 0.047 \\
\hline \multicolumn{4}{|c|}{ Osteoprotegerin (OPG; ng/L) } \\
\hline Mean (SD) & $522(106)$ & $481(142)$ & \\
\hline Median (range) & $508(389-786)$ & $455(250-1130)$ & 0.041 \\
\hline \multicolumn{4}{|l|}{ Osteocalcin $(\mu \mathrm{g} / \mathrm{L})$} \\
\hline Mean (SD) & $25739(12757)$ & $25972(9209)$ & \\
\hline Median (range) & $\begin{array}{l}20162(8570- \\
58986)\end{array}$ & $\begin{array}{l}24298(11890- \\
64063)\end{array}$ & 0.369 \\
\hline \multicolumn{4}{|c|}{ Osteopontin (OPN; $\mu \mathrm{g} / \mathrm{L})$} \\
\hline Mean (SD) & $13297(4337)$ & $10461(5773)$ & \\
\hline Median (range) & $\begin{array}{l}13364(5618- \\
24250)\end{array}$ & $\begin{array}{l}9261(1990- \\
36547)\end{array}$ & 0.009 \\
\hline \multicolumn{4}{|l|}{ Leptin (ng/ml) } \\
\hline Mean (SD) & $2.9(2.3)$ & $25.9(21.7)$ & \\
\hline Median (range) & $2.7(0.0-8.2)$ & $20.5(0.5-120.1)$ & $<0.001$ \\
\hline
\end{tabular}

merit larger studies to elucidate the potential role of TBS and bone turnover markers for fracture prediction for this condition.

What is already known on this subject:

Anorexia nervosa (AN) is often complicated by reduction of bone mass, impaired bone structure, and fractures. Microarchitecture, which adds complementary information on fracture risk can be assessed by determining Trabecular Bone Score (TBS). This has previously been done in adolescent girls with AN. Traditional bone turnover markers have also been studied in patients with AN and may add additional information on bone health.

What does this study add:

Evidence of degraded bone microarchitecture, expressed as reduced levels of TBS, has been demonstrated in adolescent girls but has not to our knowledge previously been assessed in adult patients with AN. This study demonstrates the possibility of also using TBS in adult patients with $\mathrm{AN}$ and it raises the question if AN of today necessarily is associated with an impaired bone structure to the extent previously believed. The study also demonstrates a possible novel finding of increased serum levels of osteopontin.
Table 3 Correlations between trabecular bone score (TBS) and the other various variables assessed at study inclusion using Spearman's non-parametrsic regression

\begin{tabular}{|c|c|c|c|}
\hline \multirow[t]{2}{*}{ Variable } & \multicolumn{3}{|c|}{$\begin{array}{l}\text { Trabecular bone } \\
\text { score (TBS) }\end{array}$} \\
\hline & $N$ & $R$ & $p$ \\
\hline Age at baseline (years) & 20 & -0.150 & 0.528 \\
\hline Age at menarche (years) & 18 & -0.602 & 0.008 \\
\hline Duration of anorexia (years) & 19 & 0.054 & 0.827 \\
\hline $\operatorname{BMI}\left(\mathrm{kg} / \mathrm{m}^{2}\right)$ & 20 & 0.527 & 0.017 \\
\hline Plasma calcium (mmol/L) & 19 & 0.346 & 0.147 \\
\hline Serum-ionized calcium (mmol/L) & 19 & 0.363 & 0.126 \\
\hline Serum PTH (pmol/L) & 19 & -0.026 & 0.917 \\
\hline Total serum 25(OH)D (nmol/L) & 19 & -0.174 & 0.477 \\
\hline Free serum $25(\mathrm{OH}) \mathrm{D}(\mathrm{pg} / \mathrm{ml})$ & 18 & -0.099 & 0.695 \\
\hline Plasma albumin (mmol/L) & 19 & 0.298 & 0.215 \\
\hline Plasma-creatinine $(\mu \mathrm{mol} / \mathrm{L})$ & 19 & -0.016 & 0.949 \\
\hline Serum testosterone (nmol/L) & 19 & -0.047 & 0.847 \\
\hline Serum luteinizing hormone (LH IU/L) & 19 & 0.193 & 0.430 \\
\hline $\begin{array}{l}\text { Serum follicle-stimulating hormone (FSH } \\
\text { (IU/L) }\end{array}$ & 19 & 0.091 & 0.711 \\
\hline $\begin{array}{l}\text { Plasma thyroid-stimulating hormone (TSH } \\
\mathrm{mIE} / \mathrm{L} \text { ) }\end{array}$ & 19 & 0.500 & 0.029 \\
\hline Free plasma tyroxin $(\mathrm{T} 4 \mathrm{pmol} / \mathrm{L})$ & 18 & -0.034 & 0.895 \\
\hline Plasma-ALP ( $\mu$ kat/L) & 18 & 0.035 & 0.891 \\
\hline Bone mineral density hip $\left(\mathrm{g} / \mathrm{cm}^{2}\right)$ & 20 & 0.547 & 0.013 \\
\hline T-score Hip & 20 & 0.547 & 0.013 \\
\hline Z-score Hip & 20 & 0.562 & 0.010 \\
\hline Bone mineral density lumbar spine $\left(\mathrm{g} / \mathrm{cm}^{2}\right)$ & 20 & 0.368 & 0.110 \\
\hline T-score lumbar spine & 20 & 0.368 & 0.110 \\
\hline Z-score lumbar spine & 20 & 0.268 & 0.254 \\
\hline Leptin (ng/ml) & 17 & -0.015 & 0.955 \\
\hline Dickkopf-1 (Dkk-1; ng/L) & 20 & 0.001 & 0.997 \\
\hline Osteoprotegerin (OPG; ng/L) & 20 & -0.181 & 0.444 \\
\hline Osteocalcin $(\mu \mathrm{g} / \mathrm{L})$ & 20 & -0.141 & 0.552 \\
\hline Osteopontin (OPN; $\mu \mathrm{g} / \mathrm{L})$ & 20 & 0.018 & 0.940 \\
\hline
\end{tabular}

Author contributions All authors contributed to the study conception and design. Material preparation, data collection and analysis were performed by [Pär Wanby], [Martin Carlsson], [Lars Brudin] and [Siv Ping Von]. The first draft of the manuscript was written by [Pär Wanby] and all authors commented on previous versions of the manuscript. All authors read and approved the final manuscript.

Funding Open access funding provided by Linnaeus University. This work was supported by a grant from the Medical Research Council of Southeast Sweden (FORSS).

Availability of data and material Additional data can on request be made available.

\section{Compliance with ethical standards}

Conflict of interest On behalf of all authors, the corresponding author states that there is no conflict of interest. 
Ethical approval All procedures performed in studies involving human participants were in accordance with the ethical standards of the institutional and/or national research committee and with the 1964 Helsinki declaration and its later amendments or comparable ethical standards. The study was approved by the Regional Ethical Committee, Linköping, Sweden.

Informed consent Informed consent was obtained from all individual participants included in the study.

Open Access This article is licensed under a Creative Commons Attribution 4.0 International License, which permits use, sharing, adaptation, distribution and reproduction in any medium or format, as long as you give appropriate credit to the original author(s) and the source, provide a link to the Creative Commons licence, and indicate if changes were made. The images or other third party material in this article are included in the article's Creative Commons licence, unless indicated otherwise in a credit line to the material. If material is not included in the article's Creative Commons licence and your intended use is not permitted by statutory regulation or exceeds the permitted use, you will need to obtain permission directly from the copyright holder. To view a copy of this licence, visit http://creativecommons.org/licenses/by/4.0/.

\section{References}

1. Vestergaard P, Emborg C, Støving RK, Hagen C, Mosekilde L, Brixen K (2002) Fractures in patients with anorexia nervosa, bulimia nervosa, and other eating disorders - a nationwide register study. Int J Eat Disord 32(3):301-308. https://doi.org/10.1002/eat.10101

2. Misra M, Klibanski A (2014a) Endocrine consequences of anorexia nervosa. Lancet Diabetes Endocrinol 2(7):581-592. https:// doi.org/10.1016/S2213-8587(13)70180-3

3. Grinspoon S, Thomas E, Pitts S et al (2000) Prevalence and predictive factors for regional osteopenia in women with anorexia nervosa. Ann Intern Med 133(10):790-794. https://doi.org/10.7326/00034819-133-10-200011210-00011

4. Misra M, Klibanski A (2014b) Anorexia nervosa and bone. J Endocrinol 221(3):R163-176. https://doi.org/10.1530/JOE-14-0039

5. Biller B, Saxe V, Herzog D, Rosenthal D, Holzman S, Klibanski A (1989) Mechanisms of osteoporosis in adult and adolescent women with anorexia nervosa. J Clin Endocrinol Metab 68:548-554. https ://doi.org/10.1210/jcem-68-3-548

6. Lucas AR, Melton LJ 3rd, Crowson CS, O'Fallon WM (1999) Long-term fracture risk among women with anorexia nervosa: a population-based cohort study. Mayo Clin Proc 74(10):972-977. https://doi.org/10.4065/74.10.972

7. Silva BC, Broy SB, Boutroy S, Schousboe JT, Shepherd JA, Leslie WD (2015) Fracture risk prediction by non-BMD DXA measures: the 2015 ISCD official positions Part 2: trabecular bone score. J Clin Densitom 18(3):309-330. https://doi.org/10.1016/j. jocd.2015.06.008

8. Bouxsein ML (2005) Determinants of skeletal fragility. Best Pract Res Clin Rheumatol 19(6):897-911. https://doi.org/10.1016/j. berh.2005.07.004

9. Bredella MA, Misra M, Miller KK et al (2008) Distal radius in adolescent girls with anorexia nervosa: trabecular structure analysis with high-resolution flat-panel volume CT. Radiology 249:938-946. https://doi.org/10.1148/radiol.2492080173

10. Pothuaud L, Carceller P, Hans D (2008) Correlations between grey-level variations in 2D projection images (TBS) and 3D microarchitecture: Applications in the study of human trabecular bone microarchitecture. Bone 42:775-787. https://doi.org/10.1016/j. bone. 2007.11 .018
11. Silva BC, Leslie WD, Resch $\mathrm{H}$ et al (2014) Trabecular bone score: A noninvasive analytical method based upon the DXA image. J Bone Miner Res 29:518-530. https://doi.org/10.1002/jbmr.2176

12. Harvey NC, Gluer CC, Binkley N, McCloskey EV, Brandi ML, Cooper $\mathrm{C}$ et al (2015) Trabecular bone score (TBS) as a new complementary approach for osteoporosis evaluation in clinical practice. Bone 78:216-224. https://doi.org/10.1016/j.bone.2015.05.016

13. Donaldson AA, Feldman HA, O'Donnell JM, Gopalakrishnan G, Gordon CM (2015) Spinal bone texture assessed by trabecular bone score in adolescent girls with anorexia nervosa. J Clin Endocrinol Metab 100(9):3436-3442. https://doi.org/10.1210/jc.2015-2002

14. Levy-Shraga Y, Tripto-Shkolnik L, David D, Vered I, Stein D, Modan-Moses D (2019) Low trabecular bone score in adolescent female inpatients with anorexia nervosa. Clin Nutr 38(3):11661170. https://doi.org/10.1016/j.clnu.2018.04.013

15. Carlsson M, Brudin L, Wanby P (2018) Directly measured free 25-hydroxy vitamin D levels show no evidence of vitamin D deficiency in young Swedish women with anorexia nervosa. Eat Weight Disord 23(2):247-254. https://doi.org/10.1007/s40519-017-0392-y

16. Hind K, Oldroyd B, Truscott JG (2010) In vivo precision of the GE Lunar iDXA densitometer for the measurement of total-body, lumbar spine, and femoral bone mineral density in adults. J Clin Densitom 13(4):413-417. https://doi.org/10.1016/j.jocd.2010.06.002

17. Silva BC, Boutroy S, Zhang C et al (2013) Trabecular bone score (TBS) - a novel method to evaluate bone microarchitectural texture in patients with primary hyperparathyroidism. J Clin Endocrinol Metab 98(5):1963-1970. https://doi.org/10.1210/jc.2012-4255

18. Briot K, Paternotte S, Kolta S et al (2013) Added value of trabecular bone score to bone mineral density for prediction of osteoporotic fractures in postmenopausal women: the OPUS study. Bone 57(1):232-236. https://doi.org/10.1016/j.bone.2013.07.040

19. Boutroy S, Hans D, Sornay-Rendu E et al (2013) Trabecular bone score improves fracture risk prediction in non-osteoporotic women: the OFELY study. Osteoporos Int 24(1):77-85. https://doi. org/10.1007/s00198-012-2188-2

20. Breban S, Briot K, Kolta S et al (2012) Identification of rheumatoid arthritis patients with vertebral fractures using bone mineral density and trabecular bone score. J Clin Densitom 15(3):260-266. https:// doi.org/10.1016/j.jocd.2012.01.007

21. Galusca B, Zouch M, Germain N et al (2008) Constitutional thinness: unusual human phenotype of low bone quality. J Clin Endocrinol Metab 93(1):110-117. https://doi.org/10.1210/jc.2007-1591

22. Lawson EA, Miller KK, Bredella MA et al (2010) Hormone predictors of abnormal bone microarchitecture in women with anorexia nervosa. Bone 46(2):458-463. https://doi.org/10.1016/j. bone.2009.09.005

23. Miller KK, Grinspoon SK, Ciampa J, Hier J, Herzog D, Klibanski A (2005) Medical findings in outpatients with anorexia nervosa. Arch Intern Med 65(5):561-566. https://doi.org/10.1001/archi nte.165.5.561

24. Fazeli Pouneh K, Klibanski Anne (2018) Effects of Anorexia Nervosa on Bone Metabolism. Endocr Rev 39(6):895-910. https://doi. org/10.1210/er.2018-00063

25. Maïmoun L, Guillaume S, Lefebvre $P$ et al (2014) Role of sclerostin and dickkopf- 1 in the dramatic alteration in bone mass acquisition in adolescents and young women with recent anorexia nervosa. J Clin Endocrinol Metab 99(4):E582-90. https://doi.org/10.1210/ jc.2013-2565

26. Ostrowska Z, Ziora K, Oświęcimska J et al (2016) TGF- $\beta 1$, bone metabolism, osteoprotegerin, and soluble receptor activator of nuclear factor-kB ligand in girls with anorexia nervosa. Endokrynol Pol 67(5):493-500. https://doi.org/10.5603/EP.a2016.0059

27. Lawrence Riggs B (2000) The mechanisms of estrogen regulation of bone resorption. J Clin Invest 106(10):1203-1204. https://doi. org/10.1172/JCI11468 
28. Filardi T, Carnevale V, Massoud R et al (2019) High serum osteopontin levels are associated with prevalent fractures and worse lipid profile in post-menopausal women with type 2 diabetes. $\mathrm{J}$ Endocrinol Invest 42(3):295-301. https://doi.org/10.1007/s4061 8-018-0914-0
Publisher's Note Springer Nature remains neutral with regard to jurisdictional claims in published maps and institutional affiliations. 